\section{Apolipoprotein A-I}

\author{
K. J. Lackner ${ }^{1}$ und D. Peetz ${ }^{2}$ \\ ${ }^{1}$ Institut für Klinische Chemie und Laboratoriumsmedizin, \\ Universitätsmedizin Mainz, Mainz, Deutschland \\ ${ }^{2}$ Institut für Labormedizin, Helios Klinikum Berlin-Buch, \\ Berlin, Deutschland
}

\section{Synonym(e) ApoA-I}

Englischer Begriff apolipoprotein A-I

Definition Hauptapolipoprotein der High Density Lipoproteine (HDL; s. $>$ High Density Lipoprotein).

Struktur 243 Aminosäuren; geringe, nicht vollständige posttranslationale Modifikation durch Acylierung und Phosphorylierung.

Molmasse $28,4 \mathrm{kDa}$.

Halbwertszeit 3,5-5 Tage.

Funktion - Pathophysiologie HDL und insbesondere > Prä- $\beta 1$-HDL gilt als wichtiges Akzeptorpartikel für zelluläres C Cholesterin. Insgesamt ist ApoA-I neben ApoE das für den Transport von überschüssigem Cholesterin aus der Peripherie zur Leber wichtigste Apolipoprotein. Defekte im ApoA-I-Gen führen zu vollständigen HDL-Defizienzen oder verminderten HDL-Cholesterin-Konzentrationen und erhöhen damit das Atheroskleroserisiko.

Untersuchungsmaterial - Entnahmebedingungen Serum, EDTA- oder Heparinplasma.

(C) Springer-Verlag GmbH Deutschland, ein Teil von Springer Nature 2018

A. Gressner, T. Arndt (Hrsg.), Lexikon der Medizinischen Laboratoriumsdiagnostik, Springer Reference Medizin, https://doi.org/10.1007/978-3-662-49054-9_262-1
Analytik Immunturbidimetrie, Immunnephelometrie, - Enzyme-linked Immunosorbentassay (nur bei sehr niedrigen Werten).

Konventionelle Einheit $\mathrm{mg} / \mathrm{dL}$.

Internationale Einheit $\mathrm{g} / \mathrm{L}$.

Umrechnungsfaktor zw. konv. u. int. Einheit 1:100.

Referenzbereich - Frauen 100-210 mg/dL (nur orientierend, da stark methodenabhängig).

Referenzbereich - Männer $90-180 \mathrm{mg} / \mathrm{dL}$ (nur orientierend, da stark methodenabhängig).

Referenzbereich - Kinder Keine validen Angaben; aber außer in der Neugeborenenphase nicht grundsätzlich verschieden von den Erwachsenenwerten.

Indikation Differenzialdiagnose von Veränderungen der HDL-Konzentration, v. a. HDL-Defizienzen; ansonsten klinisch keine zusätzliche Information zum HDL-Cholesterin.

Interpretation ApoA-I-Konzentrationen bieten gegenüber dem HDL-Cholesterin keine zusätzliche Information. Bei HDL-Mangelsyndromen kann die ApoA-I-Konzentration Hinweise auf die Ursache geben (vollständiges Fehlen oder starke Verminderung).

Diagnostische Wertigkeit Zusätzlich zum HDL-Cholesterin gering.

\section{Literatur}

Schwandt P, Richter O, Parhofer KG (2007) Handbuch der Fettstoffwechselstörungen, 3. Aufl. Schattauer Verlag, Stuttgart 